\title{
A monocyte function test (complement receptor enhancement) to assess the extent of bronchial carcinoma
}

\author{
MARY CARROLL, M J SMITH, MARGARET E HODSON, A B KAY \\ From the Departments of Allergy and Clinical Immunology, and of Medicine, Cardiothoracic Institute, \\ Brompton Hospital, London
}

ABSTRACT A monocyte function test (complement receptor enhancement) was undertaken on 45 patients with suspected bronchial carcinoma in whom this diagnosis was subsequently substantiated. In $38(84 \%)$ complement receptor enhancement was below a range of values previously established for monocytes from 48 healthy control subjects and from 12 patients with nonmalignant respiratory diseases. It was found that all 38 patients with reduced complement receptor enhancement had either local or widespread metastases, as determined by the chest radiograph and a variable combination of chest tomography, liver, bone and brain scanning, computed tomography, fibreoptic bronchoscopy, bone marrow aspiration, liver function tests, mediastinoscopy, and surgical assessment, where appropriate. By contrast, at the time of presentation there was no clear relationship between abnormal values in several conventional screening haematological or biochemical tests and the stage of the tumour. These results suggest that complement receptor enhancement might serve as a useful pointer to the extent of the disease, since low values were associated with extension within the chest and very low values were found with widespread metastases.

\section{Introduction}

Surgical resection remains the only form of curative treatment in lung cancer but is feasible in only a small percentage of patients. ${ }^{1}$ A successful outcome depends on accurate staging of the tumour preoperatively and only those patients with a localised tumour or disease with limited spread are usually considered for this form of treatment. ${ }^{2}$ The present staging procedures are unsatisfactory because they may fail to detect disseminated tumour spread, to judge by the low five year survival rates of patients with resected lung cancer. Mediastinoscopy and computed tomography have improved the accuracy of mediastinal staging considerably in recent years, ${ }^{3}$ although occult distant spread of tumour may remain undetected by conventional screening tests such as biochemical tests on serum and radionuclide screening.

Address for reprint requests: Professor AB Kay, Department of Allergy and Clinical Immunology, Cardiothoracic Institute, Brompton Hospital, London SW36HP.

Accepted II July 1986
Immunological abnormalities have been described in association with several neoplastic disorders. In most instances they are considered to be secondary to the underlying disease process. In particular, there have been reports of altered monocyte function in patients with various solid tumours, including bronchial carcinoma ${ }^{4}$; for example, monocyte chemo$\operatorname{taxis}^{5}$ and monocyte maturation ${ }^{6}$ have been shown to be defective in patients with metastatic lung cancer. Reports of animal experiments have indicated that tumours elaborate small molecular weight factors (6000-10000 daltons) that inhibit monocyte chemotaxis and so prevent potentially tumoricidal macrophages from accumulating at the site of developing tumours. ${ }^{7}$ Furthermore, similar material obtained from homogenates of human lung cancer was shown to inhibit chemotactic factor induced activation of normal peripheral blood monocytes as assessed by complement receptor enhancement. ${ }^{8}$ More recently we have shown that peripheral blood monocytes from patients with bronchial carcinoma showed less monocyte complement receptor enhancement than did monocytes from normal individuals and patients with non-malignant respiratory diseases. ${ }^{9}$

In general, the results of previously described 
immunological assessment, such as monocyte maturation ${ }^{6}$ and chemotaxis, ${ }^{5}$ do not distinguish clearly between subjects from control groups and individuals with malignancy. Consequently such tests as these are of limited clinical value. Contrary to our expectations, however, results of monocyte complement receptor enhancement in cells obtained from patients with bronchial carcinoma were clearly different from those obtained from control groups. Furthermore, the degree of depression of monocyte complement receptor enhancement by lung cancer appeared to be related to the extent of the disease.

For these reasons, we have compared monocyte complement receptor enhancement with a number of conventional screening tests to determine whether it might be useful in clinical practice as a means of determining the extent of the disease.

\section{Methods}

Forty five patients with lung cancer were studied at the time of diagnosis and before initiation of treatment for their tumours (table 1). There were four control groups: 12 patients with non-malignant respiratory disease (respiratory controls-namely, chronic airflow limitation (5), sarcoidosis (3), bronchiectasis (2), pulmonary fibrosis (2)); and 48 healthy controls, including seven over the age of 45 years (older healthy controls), all of whom were nonsmokers or ex-smokers; and nine who currently smoked over 15 cigarettes a day (smoking controls).

The patients with bronchial carcinoma were graded as having either localised $(n=5)$, thoracic $(n=12)$, or metastatic disease $(n=28)$ on the basis of clinical examination, chest radiography and a variable combination of chest tomography, liver, bone and brain scanning, computed tomography, fibreoptic bronchoscopy, bone marrow aspiration, liver function tests, mediastinoscopy, and thoracotomy. All five patients with localised disease underwent thorac-

Table 1 Numbers, sex, and age of the patients with bronchial carcinoma and control groups

\begin{tabular}{|c|c|c|c|c|c|}
\hline & \multicolumn{3}{|l|}{$\operatorname{Sex}$} & \multicolumn{2}{|l|}{ Age } \\
\hline & No & $M$ & $F$ & Range & (mean) \\
\hline \multicolumn{6}{|l|}{ Bronchial carcinoma* } \\
\hline Localised & 5 & 4 & 1 & $55-64$ & $(60 \cdot 0)$ \\
\hline Thoracic & 12 & 11 & $i$ & $50-74$ & $(62 \cdot 4)$ \\
\hline Metastases & 28 & 24 & 4 & $42-75$ & $(64 \cdot 2)$ \\
\hline Total & 45 & 39 & 6 & $42-75$ & $(63.2)$ \\
\hline Respiratory controls* & 12 & 7 & 5 & $62-77$ & $(66 \cdot 2)$ \\
\hline Healthy controlst & 32 & 13 & 19 & $27-35$ & $(30 \cdot 1)$ \\
\hline Older healthy controls* & 7 & 2 & 5 & $45-70$ & $(63.6)$ \\
\hline Smoking controls* & 9 & 5 & 4 & $27-35$ & $(31 \cdot 7)$ \\
\hline
\end{tabular}

*All smokers or ex-smokers.

†Non-smokers. otomy and were found to have a solitary lesion with no affected regional lymph nodes. Patients with thas racic disease had tumour in the mediastinum, contrao lateral lung, or supraclavicular lymph nodes Thoracotomy was undertaken in five of the $1 \overline{\bar{m}}$ patients in this group while the disease in the remaing der was judged to be limited to the thorax on the basis of clinical examination and the results of the remains ing diagnostic procedures described above. Meta static disease was established in 28 patients by clinicat findings and the results of one or more of the abovo investigations. One patient in this group had a tho racotomy. The respiratory controls comprised ind viduals who had developed serious complications df their conditions. They were matched with patients with bronchial carcinoma for age, smoking history and depression of serum albumin.

All patients had the following routine hae $=$ matological and biochemical tests: total an£ differential white cell counts; erythrocyte sedimen tation rate (ESR); and estimations of serum albumin? bilirubin, aspartate transaminase, $\gamma$ glutamyl trans peptidase, and alkaline phosphatase.

The monocyte complement receptor enhancem assay used a rosette technique using sheep red cello (E) sensitised with rabbit IgM $\left(E_{M}\right)$ and incubates with human $\mathrm{R} 3$ reagent, ${ }^{9}$ stabilised with suramin as source of complement. Enhancement of the com plement receptors was performed by preincubation o\$ the monocytes with the chemotactic agent f-met-leu $\overrightarrow{0}$ phe. ${ }^{9}$ Optimal increases in monocyte complemen $\bar{B}$ rosettes on monocytes from both patients and con? trols were usually achieved with $10^{-9}$ or $10^{-8} \mathrm{~mol} / \mathrm{l}$ o. f-met-leu-phe, but inhibition was generally observed at $10^{-7} \mathrm{~mol} / \mathrm{l}$. Percentage changes in monocyte com? plement rosettes (figs 1 and 2, table 2) were calculateơ as follows: monocyte rosettes (\%) with FMLP (optio mal concentrations)-monocyte rosettes (\%) with diluent alone/monocyte rosettes (\%) with dilueng alone $\times 100$.

Statistical analysis was performed by means of Wilcoxon's rank sum test for non-parametric data.

\section{Results}

The slide to slide variations in the numbers of monos cyte complement rosettes were calculated. The coefficients of variations of five replicate slides frone three separate sets of cells were $8.6 \%, 11.2 \%$, and $8.1 \%$ before enhancement and $11 \%, 5.7 \%$, an $\overline{6}$ $13.1 \%$ after incubation with f-met-leu-phe. The ${ }^{+}$ reproducibility of monocyte complement receptoro enhancement during the period of the study was assessed on control cells from three individuals, mea尺 sured on five different occasions, throughout the $2 \Phi$ month study period. The coefficients of variation 


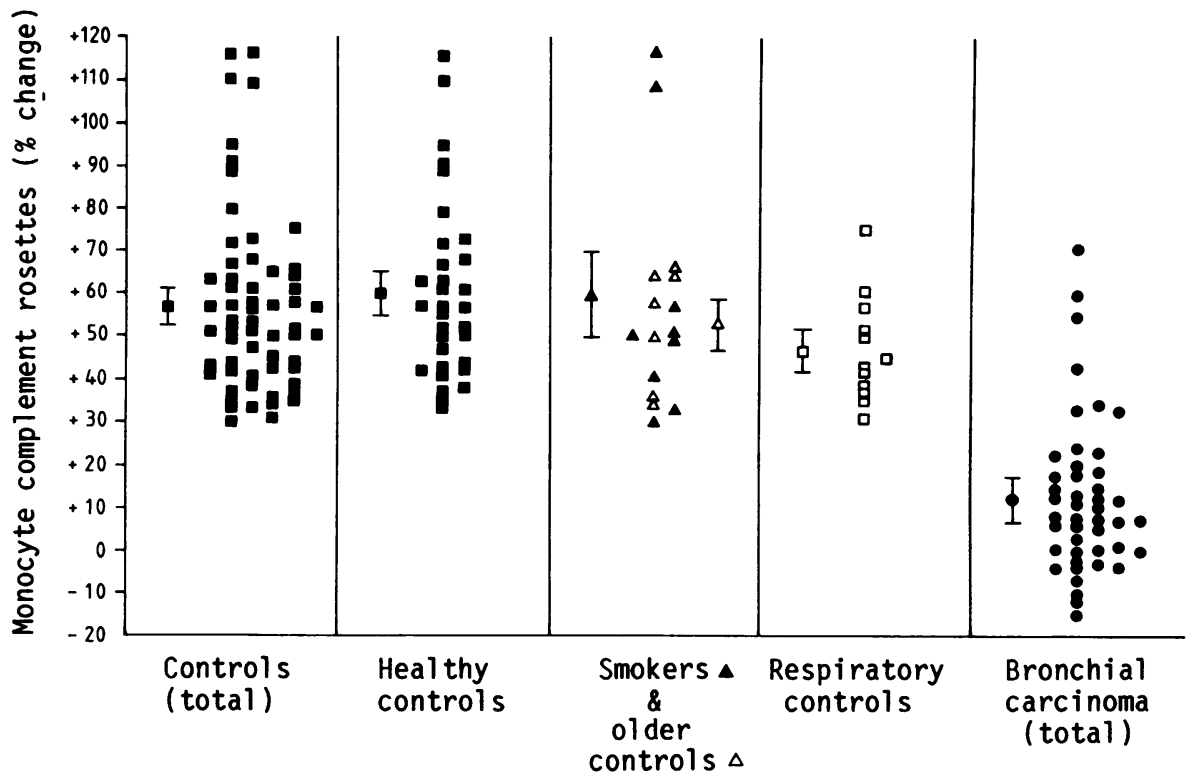

Fig 1 Monocyte complement receptor enhancement, expressed as a percentage change in rosettes, in patients with bronchial carcinoma, in all control subjects and in controls subdivided into healthy, older healthy subjects, smokers and respiratory controls.

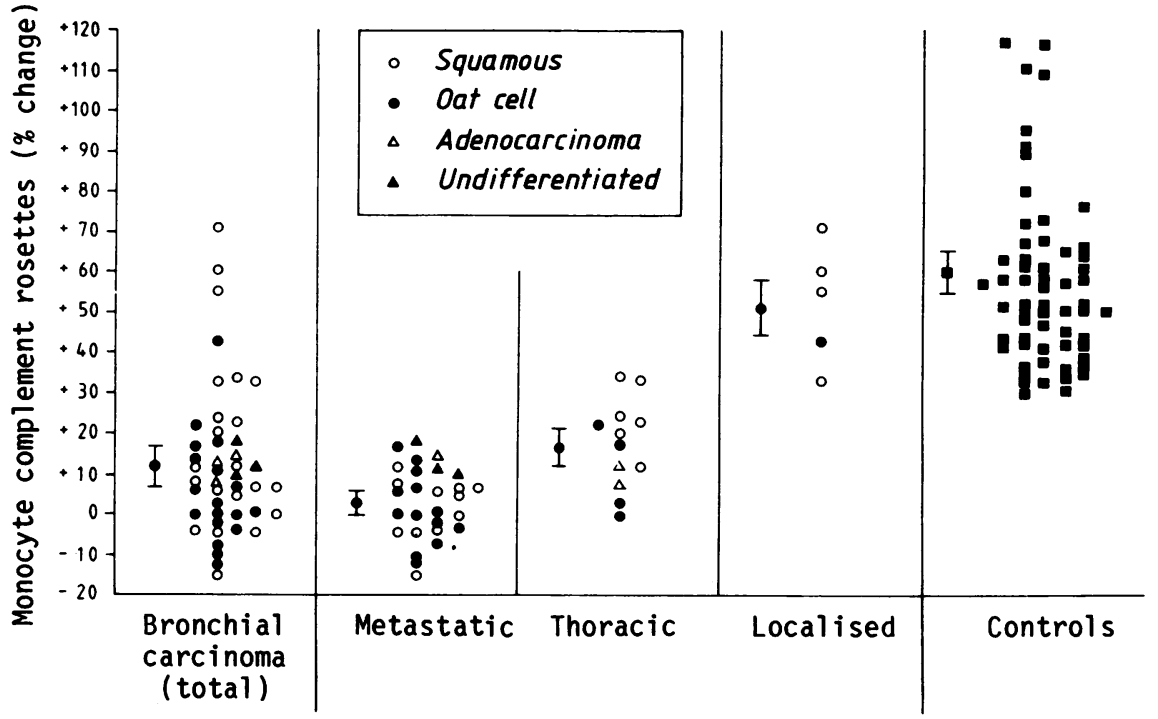

Fig 2 Monocyte complement receptor enhancement, expressed as a percentage change in rosettes, in controls, in all patients with bronchial carcinoma and in these patients subdivided according to the progression of the disease and the histological type of the tumour.

were $21 \cdot 8 \%, 24 \%$, and $14 \%$. To eliminate the additional effects of specific treatment for bronchial carcinoma on the results, the patients were studied only at the time of diagnosis. Immediately afterwards most received chemotherapy or radiotherapy or underwent an operative procecture. Consequently we were able to study only two patients with bronchial carcinoma more than once. On two and three separate occasions over six and four months respectively cells from two individuals with metastatic bronchial carcinoma 
Table 2 Monocyte complement receptor enhancement (MCRE) in relation to abnormal results in routine blood tests from patients with bronchial carcinoma at three different stages of the disease

\begin{tabular}{|c|c|c|c|c|c|c|c|c|c|}
\hline \multirow[b]{2}{*}{ Anatomical stage (n) } & \multirow[b]{2}{*}{ Low MCRE } & \multicolumn{8}{|c|}{ No (\%) of patients with abnormal laboratory test results } \\
\hline & & $L$ & $M$ & $E S R$ & $A l b$ & Bil & $A S T$ & $G G T$ & Alk phos \\
\hline $\begin{array}{l}\text { Localised (5) } \\
\text { Confined to chest }(12) \\
\text { Metastatic disease }(28)\end{array}$ & $\begin{array}{l}0 \\
10(83 \%) \\
28(100 \%)\end{array}$ & $\begin{array}{l}1(20 \%)^{*} \\
1(8 \%)^{*} \\
2(7 \%)^{*} \\
4(14 \%)\end{array}$ & $\begin{array}{l}1(20 \%) \dagger \\
1(8 \%) \dagger \\
3(11 \%)^{*} \\
1(4 \%) \dagger\end{array}$ & $\begin{array}{c}2(40 \%) \\
5(45 \%) \ddagger \\
18(67 \%) \ddagger\end{array}$ & $\begin{array}{c}1(20 \%) \\
1(8 \%) \\
14(50 \%)\end{array}$ & $\begin{array}{l}0 \\
2(17 \%) \\
9(32 \%)\end{array}$ & $\begin{array}{r}1(20 \%) \\
3(25 \%) \\
12(43 \%)\end{array}$ & $\begin{array}{l}0 \\
2(17 \%) \\
16(50 \%)\end{array}$ & $\begin{array}{r}1(20 \%) \\
2(17 \%) \\
18(64 \%)\end{array}$ \\
\hline
\end{tabular}

\footnotetext{
*Raised.

+Reduced.

$¥$ Not determined in one patient.

L-blood lymphocytes; M-blood monocytes; ESR — erythrocyte sedimentation rate; Alb-serum albumin: Bil-serum bilirubin;

AST - aspartate transaminase; GGT-glutamyl transpeptidase; Alk phos-alkaline phosphatase.
}

showed no monocyte complement receptor enhancement.

The results of monocyte complement receptor enhancement are shown in figures 1 and 2 . There were significant differences in monocyte complement receptor enhancement between patients with bronchial carcinoma (total) and healthy controls ( $p<$ $0.001)$, respiratory controls ( $p<0.001)$, older controls $(\mathrm{p}<0.001)$ and smoking controls $(\mathrm{p}<0.001)$ (fig 1). No significant differences in monocyte complement receptor enhancement were observed between the healthy controls as a whole and older controls or smoking controls, but when healthy controls were compared with respiratory controls the values did just reach significance at $p<0.05$. When the patients were divided into groups on the basis of the extent of the disease (fig 2) highly significant differences were observed: metastatic $v$ thoracic and localised $(\mathrm{p}<0.001)$, localised $v$ thoracic $(\mathrm{p}<0.005)$. The significance of the differences between all the control groups-healthy, older, smoking, and respiratory - and both the metastatic and the thoracic carcinoma groups-was $p<0.001$. By contrast, no significant difference was seen between the localised carcinoma group and any of the control groups. There was no additional association between monocyte complement receptor enhancement and the pathohistological type (that is, squamous, oat cell, adenocarcinoma, and undifferentiated) when the extent of the tumour was taken into account.

The results of routine haematological and biochemical tests, together with the monocyte complement receptor enhancement, are shown in table 2. Although no patient with localised disease had abnormal monocyte complement receptor enhancement, three out of the five patients had at least one abnormality in one of the routine tests. The single test result most frequently outside the normal range was the ESR, which was raised in $20 \%$ of the patients. Patients with thoracic disease were found to have reduced monocyte complement receptor enhancement in 10 out of 12 cases $(83 \%)$; among the other tests, the ESR was the most frequently abnormal value in five out of 11 cases $(45.5 \%)$. All 28 patients ${ }_{0}^{\omega}$ with metastatic disease had a monocyte complement $\mathrm{O}$ receptor enhancement value less than $30 \%$. This was $\vec{c}$ the lowest value obtained from the group of $48 \%$ healthy controls, including the seven older healthy controls and nine smoking controls, and 12 respiratory controls (figs 1 and 2). Although $67 \%$ of these $\vec{\varphi}$ patients with metastatic disease also had a raised ESR, and the alkaline phosphatase and $\gamma$ glutamyl ${ }^{-}$ transpeptidase activities and albumin concentration were abnormal in $64 \%, 59 \%$, and $50 \%$ respectively, the remaining patients had values within the normal range. When all the routine tests were taken together, $\frac{0}{8}$ however, an abnormality in at least one of the results $\varrho$ was seen in 25 of the 28 patients.

\section{Discussion}

We have shown that a test of monocyte function, monocyte complement receptor enhancement, $\frac{\text { 을 }}{2}$ showed reduced values on cells from patients with $\times$ bronchial carcinoma and that this was related to the $\frac{5}{3}$ stage of the disease. We have previously shown that baseline monocyte complement rosettes (that is, without enhancement) were no different when monocytes from patients with bronchial carcinoma were com- $\frac{\rho}{\square}$ pared with those from controls. ${ }^{9}$ Thus monocyte $\rightarrow$ complement receptor enhancement appears to give further information on monocyte function and might $N$ have useful diagnostic implications. Patients with localised disease had monocyte complement receptor 0 enhancement within a normal range previously estab- $\omega$ lished for healthy individuals (fig 1). There were, however, only five patients in this group and so we cannot 0 exclude the possibility that if a larger number had $\mathbb{D}$ been studied, even those patients with localised dis- $\stackrel{+}{+}$ ease might have had abnormal values, particularly if $T^{\circ}$ an individual had a large but nevertheless localised $\underset{\mathbb{D}}{\stackrel{\circ}{*}}$

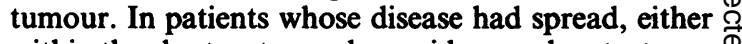
within the chest or to produce widespread metastases, $\stackrel{\triangle}{\Omega}$ monocyte complement receptor enhancement was $\bar{Q}$ 
reduced in all but two patients.

When monocyte complement receptor enhancement was compared with some established laboratory investigations of blood samples from patients with varying stages of bronchial carcinoma, no single haematological or biochemical estimation appeared to correlate with the spread of the disease to the same extent as monocyte complement receptor enhancement. Our finding appears to be more indicative of the extent of disease than that reported in a recent review of the prognostic significance of immunological tests in lung cancer. ${ }^{10}$ In that study the percentage of lymphocytes in the gradient derived cell suspensions on Ficoll-Hypaque represented the only informative test among the various tests of immune functions.

Eleven patients, who had been staged preoperatively as having localised disease, underwent thoracotomy for resection of their tumours. Five of these patients were found to have localised disease, while five were classified as having thoracic disease and one as having metastatic disease. All five with localised disease and two of those with thoracic disease (who had low "normal" values) had monocyte complement receptor enhancement within the normal range; the remaining four had a low value. Hence estimation of monocyte complement receptor enhancement might be useful in the preoperative assessment of patients, because those with a low or low normal value could undergo more specialised staging investigations-for example, computed tomography - that might identify patients with extensive disease, thereby improving the accuracy of preoperative assessment. A high value for monocyte complement receptor enhancement on the other hand might bring into doubt the importance of features that had suggested advanced disease.

Since the depressed monocyte complement receptor enhancement seen in bronchial carcinoma was greatest with the most extensive disease it could be argued that the lower monocyte complement receptor enhancement was a non-specific phenomenon due to debilitation rather than as a result of malignancy. For this reason individuals with other respiratory diseases were matched with those with metastatic bronchial carcinoma for disease severity in that both groups required hospital admission to hospital for treatment of their symptoms, which were judged clinically to be comparable. The two groups were of a similar age range and all were smokers or ex-smokers. The serum albumin, a reasonable indicator of debilitation and nutrition, was reduced in five out of the 12 respiratory controls $(42 \%)$ and fourteen of the 28 with metastatic bronchial carcinoma $(50 \%)$. As monocytes from the respiratory controls had values for monocyte complement receptor enhancement within the normal range we believe the lowered values in bronchial carcinoma are related directly to the presence of the tumour. The possibility that a lowered value is due to illness per se, however, cannot be completely excluded.

It is of interest that this test of monocyte function correlates with the extent of disease in this group of patients with bronchial carcinoma. The number of patients in this study was relatively small, but the results merit further investigation, particularly in view of the recent development of a more practical technique for measuring complement receptor expression using radiolabelled monoclonal antibody to the $\mathrm{C} 3 \mathrm{~b}(\mathrm{CR} 1)$ receptor. ${ }^{11}$ The rosette assay has much to recommend it, however, as it is simple, inexpensive, and extremely sensitive. Furthermore, the adherence of complement coated erythrocytes to phagocytic cells appears to depend on other factors besides the availability of CR1 receptor, ${ }^{12}$ and therefore the rosette technique may still be the method of choice when the studies reported here are extended.

This work was supported by the Cancer Research Campaign and the Augustus Newman Foundation.

\section{References}

1 Rossing TH, Rossing RG. Survival in lung cancer. An analysis of the effect of age, sex, resectability and histopathologic types. Am Rev Respir Dis 1982;126:771-8.

2 Ball WC. The effect of surgical treatment on the natural history of lung cancer. Am Rev Respir Dis 1983;127:1.

3 Goldstraw P, Kurzer M, Edwards D. Preoperative staging of lung cancer: accuracy of computed tomography versus mediastinoscopy. Thorax 1983;38:10-5.

4 Samak R, Edelstein R, Bogucki D, Samak M, Israel L. Testing the monocyte/macrophage system in human cancer. Biomedicine 1980;32:165-9.

5 Kay AB, McVie JG. Monocyte chemotaxis in bronchial carcinoma and cigarette smokers. $\mathrm{Br} J$ Cancer 1977;36:461-6.

6 Dent RG, Cole $P$, In vitro monocyte maturation in squamous carcinoma of the lung. $\mathrm{Br} J$ Cancer 1981;43:486-95.

7 Snyderman R, Pike MC. An inhibitor of macrophage chemotaxis produced by neoplasm. Science 1976;192:370-2.

8 Glass EJ, Abell CA, Kay AB. Inhibition of monocyte complement receptor enhancement by low molecular weight material from human lung cancers. Clin Exp Immunol 1981;43:540-8.

9 Carroll M, Lukacs K, Hodson M, Kay AB. Defective chemotactic factor-induced monocyte complement receptor enhancement in lung cancer. Clin Exp Immunol 1983;54:785-92.

10 Check IJ, Hunter RL, Karrison T, De Meester TR, Go- 
lomb HM, Vardimani J. Prognostic significance of immunological tests in lung cancer. Clin Exp Immunol 1981;43:362-9.

11 Hogg N, Ross GD, Jones DB, Slusarenko M, Walport MJ, Lachmann PJ. Identification of an anti-monocyte monoclonal antibody that is specific for membrane complement receptor type one $\left(\mathrm{CR}_{1}\right)$. Eur J Immunol
1984;14:236-43.

12 Richerson HB, Walsh GM, Walport MJ, Moqbel $\mathrm{R}, \overrightarrow{\overrightarrow{5}}$ Kay AB. Enhancement of human neutrophil complement receptors: a comparison of the rosette technique with the uptake of radio-labelled anti-CR monoclonal antibody. Clin Exp Immunol 1985;62:442-8. 